\title{
PERIPHERAL VASCULAR ACTION OF ESTROGEN IN THE HUMAN MALE ${ }^{1}$
}

\author{
By SAMUEL R. M. REYNOLDS AND FRANCIS I. FOSTER \\ (From the Department of Physiology, Long Island College of Medicine, Brooklyn, New York)
}

(Received for publication August 3, 1939)

The use of estrogen, in some women, for the relief of the severe neurovascular disturbances of the menopause is an established therapeutic measure $(1,2,3,4,5,6)$ although its specificity may be doubted in certain instances $(1,7)$. In spite of its failure to act in all cases there is no doubt that in the majority of selected patients the relief is specifically attributable to the estrogen.

Injection of this hormone is followed by a reduction in the gonadotropic hormone content of the blood and urine $(2,6)$, and usually a subsidance of the vascular disturbances. We are uncertain as to whether the reduction in the amount of gonadotropin in the urine is directly related to the symptomatic relief, or only indirectly so through a more deep-seated response of the body to the hormone. Not all climacteric women having a high gonadotropin content in their urine suffer from neurovascular disturbances. Consequently, the mechanism of the action of estrogen on the circulatory system remains to be defined. The present experiments were designed to obtain some objective measure that might be useful in this respect.

While it is generally recognized that estrogens are without demonstrable effect upon the mean level of arterial blood pressure $(8,9,10,11,14$, $15)$, evidence is accumulating to show that the effects of estrogen on the peripheral circulation are quite widespread throughout the body, and are of a definite character. The following facts indicate this: the injection of estrogen causes swelling and changes in the water content of the sex-skin in certain primates (12); estrogen causes engorgement of the vessels in the nasal mucosa, including that of women (13); the injection of estrogen in the human is followed by a fall in capillary pressure and dilatation of the nail-bed

1 Supported by grants from the Committee on Endocrine Research of the National Research Council, the Committee on Scientific Research of the American Medical Association, and in part by a grant from the Josiah Macy, Jr. Foundation. capillary vessels (14); estrogen causes a decrease of venous pressure in the hand (15); and, finally, estrogen causes a change in the water content of the skin of the rat within a few hours (16) which is qualitatively comparable to that occurring in the uterus and vagina $(16,17)$. This list is extended in the present work by observations on changes in skin temperature and in finger-volume following the injection of estrogen. An increase in finger-volume, without venous occlusion, is indicative of an augmented capacity of the small blood vessels in the fleshy parts of the finger, while changes in the temperature of the skin reflect alterations in the local rate of blood flow (18).

\section{SUBJECTS, PREPARATIONS AND METHODS}

Since the observations were intended to be of a preliminary nature, adult human males were used in this study in order to establish a convenient objective criterion of the peripheral vascular action of estrogen. It was deemed unnecessary and perhaps unwise to use female subjects with normal menstrual cycles, for a more complete study of the vascular actions of estrogen in menopausal women will logically follow this preliminary study. The subjects, twenty in all, were eighteen men in the third decade of life and two in the fourth decade, all believed to be in good health at the time and apparently normal in every respect. One subject (J. di P.), however, had a positive chest-plate three months after the experiment, although it is not probable that incipient tuberculosis would affect, or be affected by, the estrogen.

Single observations on the effect of the estrogen were made on all subjects with the exception of three who received two injections of estrogen, and one subject who received nine injections. In all but one of the positive cases noted in Table I, corn oil alone was used at least once. No individual received more than one injection of the hormone in any one week. The subjects either 
TABLE I

Summary of data from adult human males receiving estrogen intramuscularly

(See text for description)

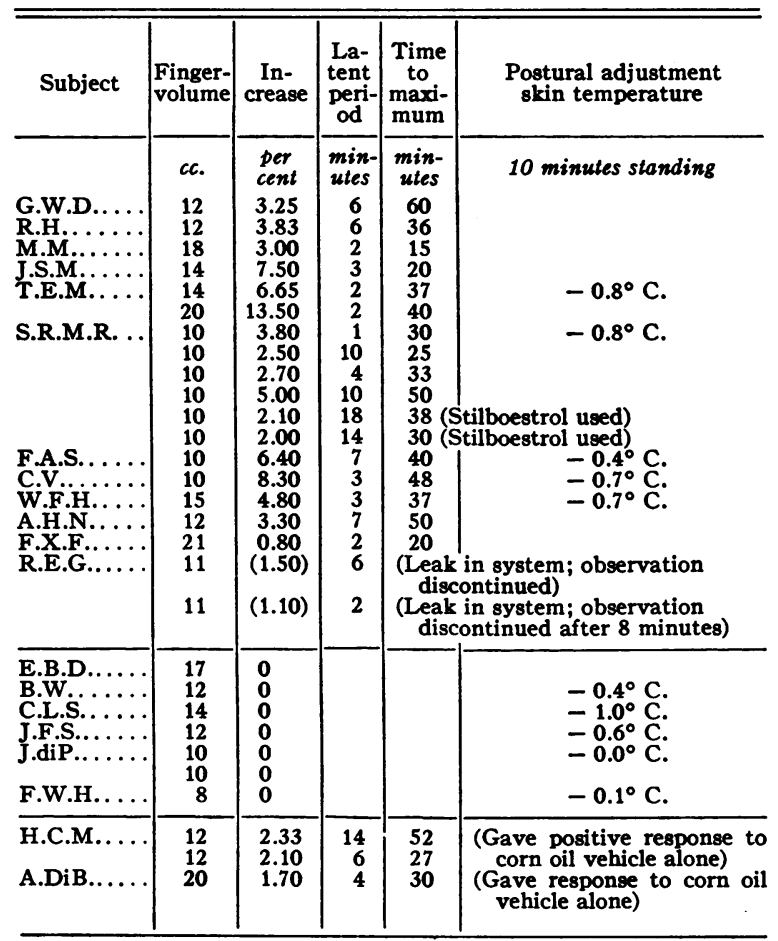

knew nothing of what was being injected, other than that it was a harmless oily preparation, or they knew that estrogen or the inert oil vehicle was to be used. The exception to this was in early experiments on one of us (S. R. M. R.), at which time only the active hormone was available. After the first few observations the injections were made as unknowns.

The preparations used were Amniotin (Squibb), containing 10,000 (predominantly estrone) units per cubic centimeter, and the corn oil vehicle alone prepared in ampules exactly like those containing the estrogen. Stilboestrol (4:4' dihydroxy $\alpha, \beta$ diethylstilbene, a synthetic compound having estrogenic properties), $1.0 \mathrm{mgm}$. per cc., was used twice. $^{2}$

In an experiment, the subject was seated comfortably, the arm supported snugly in a holder so that a finger was held without constriction in a volume-recorder of the type devised by Johnson (19). The recording droplet oscillated with each

$2 \mathrm{We}$ are indebted to Dr. J. A. Morrell for generous supplies of these preparations. pulse beat, with readings easily obtainable to 0.01 cc. Records were also kept of the temperature in the plethysmograph, the room temperature, and the skin temperature measured on the nail-bed of the finger next to the one in the apparatus. The temperature was recorded by means of a Leeds and Northrop potentiometer designed especially for measuring body temperatures and calibrated in degrees Centigrade and degrees Fahrenheit. The thermocouple was a twenty guage iron-constantan junction; the system was sensitive to $0.1^{\circ} \mathrm{C}$. Each experiment consisted of a period of control recording lasting twenty to sixty minutes. After conditions became constant (except two instances in which the subjects were nervous), injection was made intramuscularly into the triceps muscle of the free arm. Readings were made at twominute intervals for a period of twenty to forty minutes, after which readings were made at fouror five-minute intervals until from fifty minutes to an hour had elapsed.

\section{RESULTS}

The results noted in detail in Table I are summarized in Table II. Here it will be seen that

TABLE II

General summary of data contained in Table I

\begin{tabular}{|c|c|c|c|c|c|c|}
\hline $\begin{array}{l}\text { Types of response } \\
\text { to estrogen }\end{array}$ & $\begin{array}{c}\text { Num- } \\
\text { ber } \\
\text { of } \\
\text { sub- } \\
\text { jects }\end{array}$ & $\begin{array}{c}\begin{array}{c}\text { Number } \\
\text { of re- } \\
\text { sponses } \\
\text { to }\end{array} \\
\text { estrogen } \\
\text { made }\end{array}$ & $\begin{array}{l}\text { Re- } \\
\text { sponse } \\
\text { to } \\
\text { corn } \\
\text { oil }\end{array}$ & $\begin{array}{l}\text { Aver- } \\
\text { age } \\
\text { in- } \\
\text { crease }\end{array}$ & $\begin{array}{l}\text { Aver- } \\
\text { age } \\
\text { latent } \\
\text { period }\end{array}$ & $\begin{array}{l}\text { Aver- } \\
\text { age } \\
\text { time } \\
\text { to } \\
\text { maxi- } \\
\text { mum }\end{array}$ \\
\hline $\begin{array}{l}\text { Positive } \\
\text { response to } \\
\text { estrogen ....... }\end{array}$ & 12 & 19 & 0 & $\begin{array}{l}\text { per } \\
\text { cent } \\
4.6\end{array}$ & $\begin{array}{c}\underset{\min -}{\text { utes }} \\
5.7\end{array}$ & $\begin{array}{c}\text { min- } \\
\text { utes } \\
35.9\end{array}$ \\
\hline 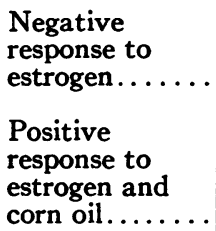 & 6 & 7 & - & 2.0 & 0 & 36.0 \\
\hline
\end{tabular}

two main types of response were obtained. In some subjects there was no discernible effect of estrogen upon finger-volume or skin temperature ( ix subjects) while in others (twelve subjects), the finger-volume increased appreciably, although there was no noticeable change in skin temperature. In general, the response had the following 


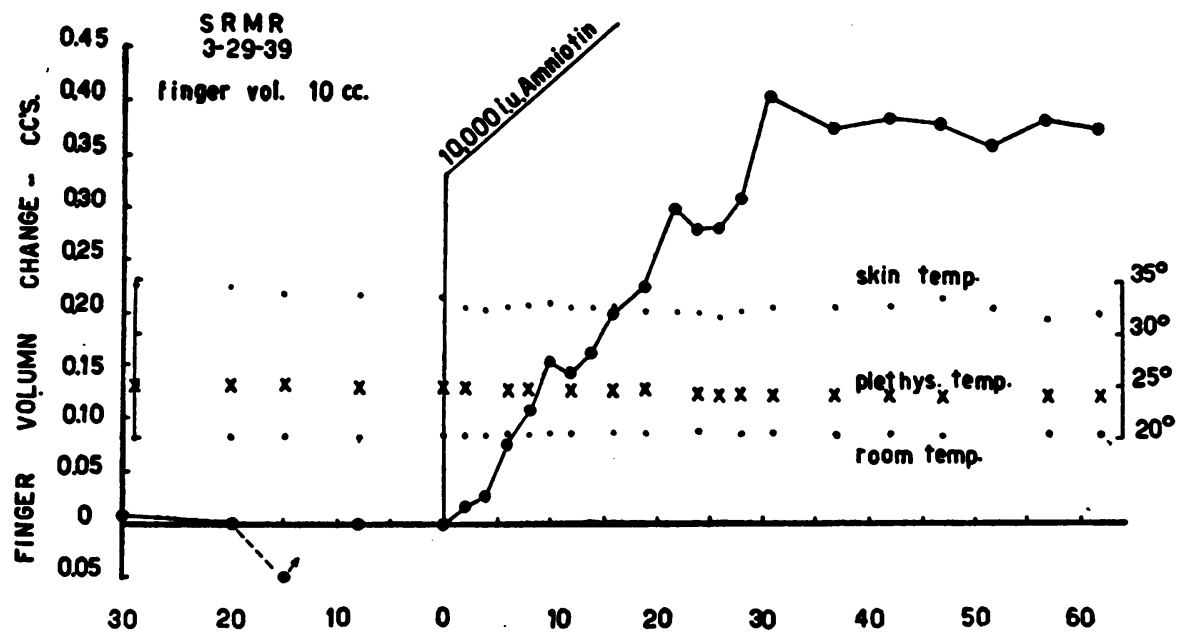

MINUTES

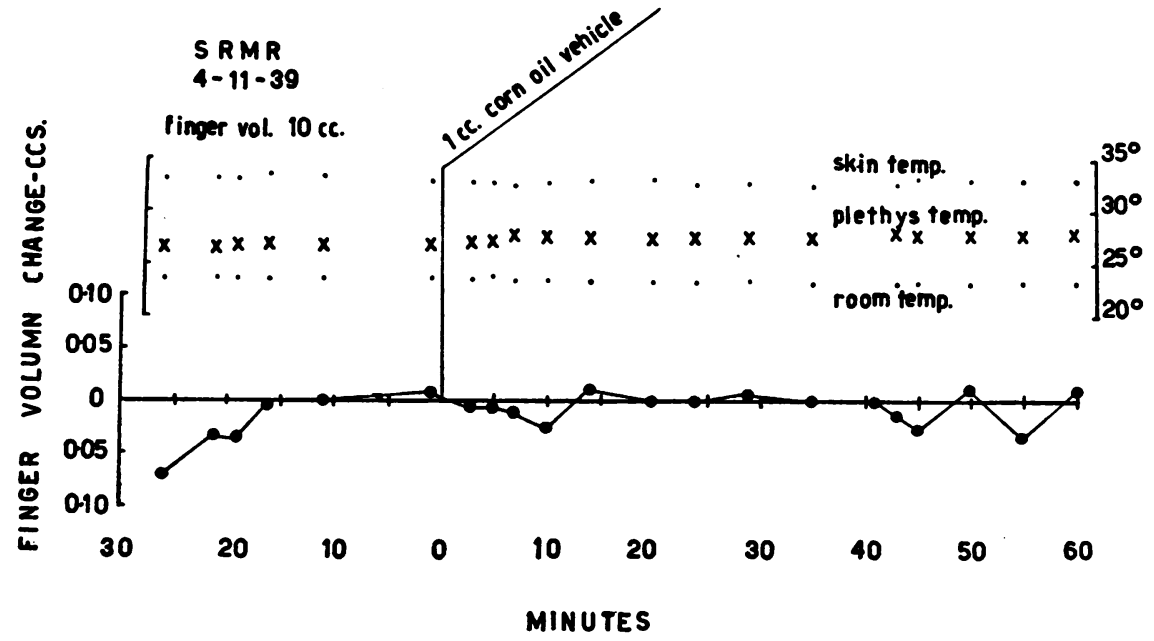

Fig. 1. Response of Increased Finger-volume to the Injection of Estrogen in Corn Oil (top) and to Corn Oil Alone (bottom) in a Subject with a Fingervolume of 10 cc. In the Plethysmograph

features: Within three to fifteen minutes, the volume of the finger begins to increase, not infrequently following a transient decrease (vasoconstriction) resulting from nervousness at the time of injection; the finger-volume becomes steadily larger for at least half an hour, although more often the period of change lasts from fortyfive minutes to an hour; the finger stays large for a period in excess of the maximum time of observation (two hours).

The average gross increase was $0.67 \mathrm{cc}$. (average finger-volume, $14 \mathrm{cc}$.), although this varied considerably. In one subject (S. R. M. R., finger- volume, $10 \mathrm{cc}$.$) , the smallest change observed$ was about 0.15 cc., the maximum, about 0.55 cc. These observations were made between January and July, although the magnitude of the response did not appear to vary with the season. In several subjects the response was as great as 0.9 to $1.0 \mathrm{cc}$. (finger-volumes of 12 to $14 \mathrm{cc}$.), or a percentage change of 6.5 to 8.3 . The average percentage increase in finger-volume, however, was only 4.6. In order to appreciate the extent of this, it is necessary to note that the fleshy part of four embalmed fingers comprised 56 per cent of the total finger-volume. It is to this part of 
the finger that the vascular alterations are limited. Accordingly, the percentage increase is in reality about double the value stated here and in Tables I and II.
The skin temperature remained constant or fluctuated slightly, unless vasoconstriction occurred. The temperature of the plethysmograph likewise did not vary, despite the increased amount
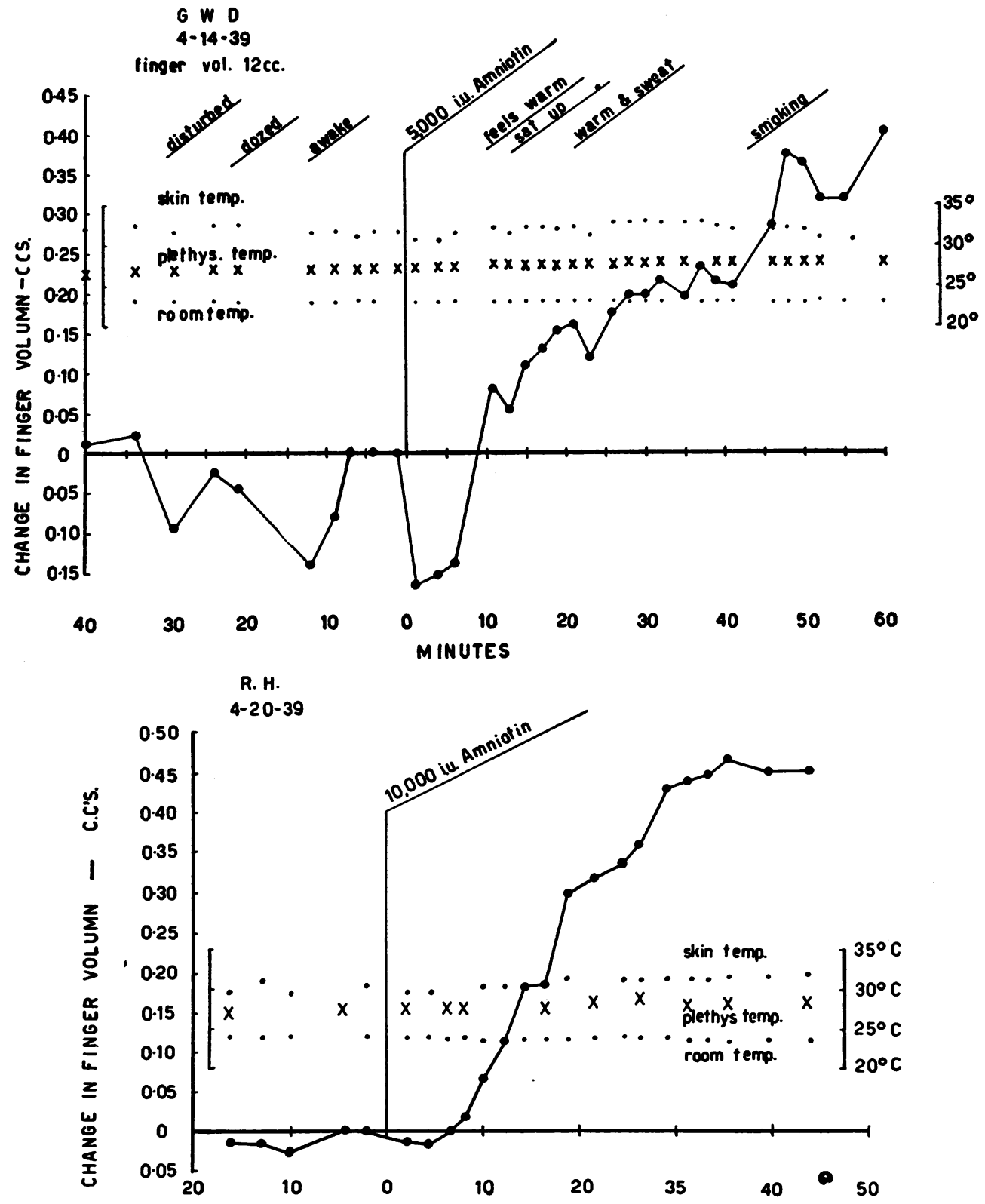

MINUTES

Fig. 2. Records of the Response of Increased Finger-volume to Administration of Estrogen in Two SubJects

Subject G. W. D. was nervous, as reflected in the variable base line during the control period and the fluctuations in skin temperature, indicating alterations in the rate of blood flow through the skin. Subject $R$. H. had a variable skin temperature at first, although this became more constant as the finger-volume increased to a plateau. 
of blood in the finger. One must conclude, therefore, that the increase in the volume of the finger after estrogen is not associated with a significant increase in the rate of blood flow, and that the heat dissipates rapidly as the finger-volume change takes place slowly. It has been characteristically observed, however, that, in some subjects much more than in others, the initial phase of the rise in finger-volume is associated with a transient feeling of warmth over the body, and especially over the face, neck, chest and upper arms. Occasionally there is a feeling of clamminess as the subject perspires. At such times the finger-volume may diminish owing to vasoconstriction resulting from the cool stimulus that necessarily follows loss of heat by rapid evaporation of sweat. This sensation should in no way be construed as a simulated menopausal flush since it is the normal response of the body to stimulation of warm receptors as the warm blood first moves into the skin. The mechanism is in all probability comparable to the paradoxical cold and warm sensations that can be elicited in normal persons under suitable circumstances (20).

Differing from either of the two types of response described above is a third which occurred in two subjects (H. M. and A. DiB.). In these cases, an increase in finger-volume was observed after injection of Amniotin, although an equally large response was obtained after injection of the corn oil vehicle alone. Consequently, these two subjects are not included in the group of individuals considered to have responded specifically to the estrogen.

\section{DISCUSSION}

Variations in response to estrogen. As noted in Table II, approximately two-thirds of the subjects responded to injection of the estrogen. Six subjects showed no response whatever. The reason for this is not known. Unsuccessful attempts have been made to correlate the failure to respond with other conditions (e.g., blood pressure levels, skin coloring, constitutional type, vasomotor instability, tendency to perspire, sensitiveness to heat and cold, etc.). There is but one correlation that appears suggestive, namely, the vasomotor adjustment that takes place in the skin of the lower leg during the first ten minutes of standing from a reclining position ( $c f .21$ ). The data suggest that those subjects who fail to respond to estrogen show less marked vasoconstriction of the skin vessels (fall of skin temperature) upon standing than do those who respond to estrogen. One exception to this was noted, however, wherein the skin temperature diminished one degree Centigrade after eight minutes, yet the subject did not respond to the hormone (C. L. S.). This subject was by far the most muscular of the individuals used in these experiments, although the bearing of this fact on the problem at hand is not evident.

Whatever the reason for the failure of some individuals to give the peripheral vascular response to estrogen may be, the fact remains that in a majority of the males studied in this series the response to estrogen was prompt in onset and definite in degree, while corn oil alone failed to give such a response. Whether or not the androgen level of a subject is a modifying factor, serving to potentiate or inhibit the vascular reaction to estrogen, is not known, although it is probable that this and other unappreciated endocrine factors exert a modifying action on the vascular response to estrogen.

Site of the vascular action of estrogen. A number of considerations point to the fact that the vasodilatation resulting from administration of estrogen involves the smallest blood vessels, namely, the capillaries and venules of the skin. In the first place, if arteriolar dilatation were involved, an increase in the rate of blood flow would occur and this would bring about a sustained increase in skin temperature. Such is not the case, however. Secondly, Carloni observed (14) that dilatation of the nail-bed capillaries after administration of estrogen occurs with a simultaneous decrease of capillary blood pressure. Systolic and diastolic blood pressures in the brachial artery are unaffected. This result could be accomplished in subjects with normal blood pressure only by vasodilatation beyond the arterioles. Lastly, direct observation of the action of estrogen administered intramuscularly to ovariectomized rabbits proved that vasodilatation in the ear of the rabbit involves the smallest blood vessels lying beyond the arterioles (22). These smallest vessels do not receive a sympathetic nerve 
supply (23), so it is necessary to conclude tentatively that the vasodilating action of estrogen in susceptible individuals is mediated by another, possibly direct, mechanism. It would appear to be significant in this respect that the dilating effect of estrogen on the vessels of the rabbit's ear may be inhibited by prior injection of atropine (22). This observation is in accord with the effect of atropine on the intense hyperemia which estrogen brings about in the uterus $(14,24)$. It may be, therefore, that the peripheral vascular action of estrogen upon certain parts of the systemic circulation resembles qualitatively, though in miniature, the recognized effects of estrogen upon the blood vessels of the uterus. Further work is necessary to render this conclusion certain, while its relation to the well-established effect of estrogen upon the neurovascular disturbances of the menopause remains to be demonstrated by direct observation upon women who require such treatment.

\section{SUM MARY}

1. The effect of intramuscular injection of estrogen upon the volume and skin temperature of the finger was measured in a group of twenty adult human male subjects.

2. Approximately two-thirds of the subjects showed an effect involving an increase in fingervolume, commencing a few minutes after injection and continuing from thirty to sixty minutes. A plateau level is attained which is sustained for the period of observation (maximum time up to two hours). The average percentage increase in finger-volume was 4.6. No change in skin temperature was noted in such cases.

3. Injection of the corn oil vehicle alone (as an unknown) had no such effect on finger-volume in these subjects.

4. The character of the response, along with other established facts regarding the vascular effects of estrogen, indicates that it depends upon dilatation of the small vessels in the skin beyond the arterioles. There is no measurable increase in the rate of blood flow in the skin.

5. The failure of estrogen to bring about dilatation of the skin vessels in some subjects is unexplained.

\section{BIBLIOGRAPHY}

1. Fluhmann, C. F., Menstrual Disorders. Saunders, Philadelphia, 1939.

2. Frank, R. T., Goldberger, M. A., and Salmon, U. J., Menopause: symptoms, hormonal status, and treatment. New York State J. Med., 1936, 36, 1363.

3. Albright, F., Studies on ovarian dysfunction. III. The menopause. Endocrinology, 1936, 20, 24.

4. Mazer, C., and Israel, S. L., Symptoms and treatment of menopause. M. Clin. North America, 1935, 19, 205.

5. Novak, E., Menopause and its management. J. A. M. A., 1938, 110, 619.

6. Salmon, U. J., and Frank, R. T., Effect of emmenin on gonadotropic hormone excretion in castrates and spontaneous menopause. Endocrinology, 1937, 21, 476.

7. Pratt, J. P., and Thomas, W. L., Endocrine treatment of menopausal phenomena. J. A. M. A., 1937, 109, 1875.

8. Parkes, A. S., The Internal Secretions of the Ovary. Longman's, Green and Co., New York and London, 1929.

9. Laqueur, E., Hart, P. C., and de Jongh, S. E., Ueber weibliches Sexualhormone (menformon) das Hormon des Östrichen Zyklus. IV. Einfluss auf den Stoffwechsel Widerstandvermögen gegen physikalische und ander Eingriffe. Deutsche med. Wchnsch., 1926, 52, 1331.

10. Kunde, M. M., D'Amour, F. E., Gustavson, R. G., and Carlson, A. J., Effect of estrin administration on reproductive and blood vascular systems: thyroid, thymus, hypophysis, adrenals, kidneys, liver and spleen. Am. J. Physiol., 1931, 96, 677.

12. Aykroyd, O. E., and Zuckerman, S., Factors in sexual-skin oedema. J. Physiol., 1938, 94, 13.

13. Mortimer, H., Wright, R. P., Bachman, C., and Collip, J. B., Effect of administration of oestrogenic hormones on nasal mucosa of monkey (Macaca mulatta). Proc. Soc. Exper. Biol. and Med., 1936, 34, 535 .

14. Carloni, E., L'azione degli estratti ovarici sull'atteggiamento dei capillari e sulla loro pressione, nelle varie fasi della rivoluzione funziozionale uteroovarica. Arch. di ostet. e ginec., 1930, 17, 327.

15. Valle, G., Studio sulla pressione venosa in rapporto ad alcune condizioni normali patologiche e sperimentali della donna non gravida. Ann. di ostet. e ginec., 1934, 56, 1011.

16. Zuckerman, S., Changes in the water-content of organs and tissues as a result of stimulation by oestradiol. Nature, 1939, 143, 521.

17. Astwood, E. B., Six-hour assay for quantitative determination of estrogen. Endocrinology, 1938, 23, 25.

18. Lewis, T., Blood Vessels of the Human Skin and their Responses. Shaw, London, 1927. 
19. Johnson, C. A., Effect of amyl nitrite upon finger volume. J. Lab. and Clin. Med., 1931-32, 17, 59.

20. Bazett, H. C. Physiological responses to heat. Physiol. Rev., 1927, 7, 531.

21. Mayerson, H. S., and Toth, L. A., Influence of posture on skin and subcutaneous temperatures. Amer. J. Physiol., 1939, 125, 474.
22. Reynolds, S. R. M., and Foster, F. I., Peripheral vascular action of oestrin. Amer. J. Physiol. (Proc.), 1939, 126, 606.

23. Grant, R. T., Further observations on vessels and nerve of rabbit's ear, with special reference to effects of denervation. Clin. Sc., 1935-36, 2, 1.

24. Pompen, A. W. M., De Invloed van Menformon op der Baarmoeder. Thesis, Amsterdam, 1933. 